\title{
PENELITIAN CAMPURAN ASPAL BETON DENGAN MENGGUNAKAN FILLER BUNGA PINUS
}

\author{
April Gunarto ${ }^{1}$, Agata Iwan Candra ${ }^{2}$ \\ ${ }^{1,2}$ Fakultas Teknik Universitas Kadiri
}

e-mail : april_gunarto@unik-kediri.ac.id,iwan_agata@unik-kediri.ac.id

\begin{abstract}
This study aims to determine the mixture of Pine Flowers using the Marshall method, and to determine the optimum asphalt content produced in concrete asphalt mixture with Pine Flower fillers, reviewed from the Marshall reserves, flow, VIM, VMA,VFB, and Marshall quotient (MQ). The concrete asphalt mixture method in this study used AC 60/70 oil asphalt. This study consisted of 5 samples, each using different asphalt levels, namely: 5\%, 5.5\%, 6\%, 6.5\%, 7\%. With each sample consisting of 3 variants of sample specimens. This research was conducted at the Technical Laboratory, the university attended. The stages of the study included coarse aggregate of the solid rock held by filter no. $8(2.36 \mathrm{~mm})$, fine aggregate with brantas river sand passes the no. $8(2.36 \mathrm{~mm})$, and fillers use pine ashes by passing filter no. $200(0.075 \mathrm{~mm})$. The results of this study about Marshall characteristics obtained Optimal Asphalt levels of 6.5\% with a mean Stability value of 1417, a mean Flow value of $3.6 \mathrm{~mm}$, a mean value of VIM(voids In Mix) 4.11\%, a mean value of VMA (Void In Mineral Aggregate 16.69\%, VFB (Void Filled Bitumen) mean value 73.57\%, and Marshall quotient (MQ) mean value 314 $\mathrm{kg} / \mathrm{mm}$.
\end{abstract}

Keywords: Concrete Asphalt, Marshall Method, Pine Flowers

\begin{abstract}
ABSTRAK
Penelitian ini bertujuan untuk menentukan campuran Bunga Pinus menggunakan metode Marshall, dan untuk menentukan kadar aspal optimal yang dihasilkan dalam campuran aspal beton dengan pengisi Bunga Pinus, ditinjau dari cadangan Marshall, aliran, VIM, VMA, VFB, dan hasil bagi Marshall (MQ). Metode campuran aspal beton dalam penelitian ini menggunakan aspal minyak AC 60/70. Penelitian ini terdiri dari 5 sampel, masing-masing menggunakan kadar aspal yang berbeda, yaitu: 5\%, 5,5\%, 6\%, 6,5\%, 7\%. Dengan masing-masing sampel terdiri dari 3 varian spesimen sampel. Penelitian ini dilakukan di Laboratorium Teknis, universitas hadir. Tahapan penelitian termasuk agregat kasar dari batuan padat yang dipegang dengan filter no. 8 (2.36 mm), agregat halus dengan pasir sungai brantas melewati no. 8 (2.36mm), dan pengisi menggunakan abu pinus dengan melewati no filter. 200 (0,075mm). Hasil penelitian ini tentang karakteristik Marshall diperoleh kadar Aspal Optimal 6,5\% dengan nilai Stabilitas rata-rata 1417, nilai rata-rata Arus 3,6 mm, nilai rata-rata VIM (void Dalam Campuran) 4,11\%, nilai rata-rata VMA ( Void Dalam Mineral Agregat 16,69\%, VFB (Void Filled Bitumen) nilai rata-rata 73,57\%, dan Marshall quotient (MQ) nilai rata-rata $314 \mathrm{~kg} / \mathrm{mm}$.
\end{abstract}

Kata Kunci: Aspal Beton, Metode Marshall, Bunga Pinus 


\section{PENDAHULUAN}

Aspal beton sebagai bahan untuk konstruksi jalan sudah lama dikenal dan digunakan secara luas dalam pembuatan jalan. Penggunaannya pun dinegara Indonesia dari tahun ketahun semakin meningkat. Hal ini disebabkan karena aspal beton mempunyai kelebihan dibanding bahan lainnya, disamping harga yang relatif lebih murah dibanding beton pada umumnya, kemampuan dalam mendukung beban berat kendaraan cukup tinggi, dapat dibuat dari bahanbahan lokal yang tersedian dan mempunyai ketahanan yang baik terhadap cuaca. Jenis perkerasan ini merupakan campuran merata antara agregat dan aspal sebagai bahan pengikat pada suhu tertentu. Ada empat sifat dasar aspal beton yang harus diperhatikan dalam merencanakan campuran aspal beton, seperti stabilitas, durabilitas, fleksibilitas dan mempunyai tahanan terhadap selip (skid resistance ). Apabila keempat sifat tidak dapat diwujudkan secara optimum, maka perencanaan campuran aspal beton tidak dapat dilakukan. Karena campuran yang baik harus mempunyai kecukupan dalam keempat sifat di atas. Bahan pengisi ( filler ) dalam campuran aspal beton adalah bahan yang lolos saringan No.200 (0,075 $\mathrm{mm})$. pengisiannya dilakukan secara terstruktur, jika terlalu banyak bahan pengisi dalam campuran akan menyebabkan aspal beton menjadi sangat kaku dan mudah retak meskipun telah dilakukan penambahan aspal yang lumayan banyak guna memenuhi workability. Sebaliknya kekurangan bahan campuran akan berakibat lentur sehingga mudah terdeformasi oleh roda kendaraan dan menghasilkan jalan yang bergelombang. Macam bahan pengisi yang dapat digunakan seperti; abu batu, portland cement ( PC ), debu dolomite, abu terbang, debu tanur tinggi pembuat semen dan Bunga Pinus (dihaluskan untuk filler). Pada penelitian ini kadar bahan pengisi dibatasi antara $2 \%$ hingga $8 \%$ dari berat total campuran aspal beton. Jenis bahan pengisi dipilih Bunga Pinus yang dihaluskan.

\section{METODE PENELITIAN}

\subsection{Material Aspal}

Aspal didefinisikan sebagai material berwarna hitam atau coklat tua, pada temperatur ruang berbentuk padat sampai agak padat. Jika dipanaskan sampai suhu temperatur tertentu aspal dapat menjadi lunak/cair sehingga dapat membungkus partikel agregat pada waktu pembuatan aspal beton atau dapat masuk ke dalam pori-pori yang ada pada penyemprotan/penyiraman pada perkerasan macadam maupun pelaburan. Lapis aspal beton merupakan jenis tertinggi dari perkerasan yang merupakan campuran dari bitumen dengan agregat bergradasi dan cocok untuk 
jalan yang layak dilalui kendaraan berat. Suhu pencampuran ditentukan berdasarkan jenis aspal yang akan digunakan. Jika digunakan semen aspal, maka suhu pencampuran umumnya antara $145^{\circ}-155^{\circ} \mathrm{C}$, sehingga disebut aspal beton campuran panas. Campuran ini lebih dikenal juga dengan nama hotmix.

\subsection{Agregat Kasar}

Fraksi agregat kasar untuk agregat ini adalah agregat yang tertahan di atas saringan 2,36 mm (No.8), menurut saringan ASTM. Agregat ini menjadikan perkerasan lebih stabil dan mempunyai skid resistance (tahanan terhadap selip) yang tinggi sehingga lebih menjamin keamanan berkendara. Agreagat kasar ini harus tahan terhadap abrasi bila digunakan pada aspal beton, untuk itu nilai Los Angeles Abrasion test harus dipenuhi. Agregat kasar yang digunakan adalah batu koral dari penggilingan batu di daerah semen tertahan saringan no.1/2 , 3/8, 4, dan 8. Parameter agregat kasar untuk campuran lataston terdiri dari batu pecah atau kerikil pecah yang bersih, kering, kuat, awet dan bebeas dari bahan lain yang mengganggu seperti lumpur, agregat kasar harus mempunyai angularitas seperti yang didefinisikan sebagai persen terhadap berat agregat yang lebih besar dari $4,75 \mathrm{~mm}$ dengan muka bidang pecah satu atau lebih bedasarkan uji menurut SNI 7619 : 2012 dan harus memenuhi spesifikasi seperti yang disyaratkan.

\subsection{Agregat Halus}

Agregat halus adalah agregat hasil pemecah batu yang mempunyai sifat lolos saringan No.8 (2,36 mm), sesuai SNI 03-6819-2002. Fungsinya untuk menyediakan stabilitas dan mengurangi deformasi permanen dari perkerasan melalui keadaan saling mengunci dan gesekan antar butiran. Agregat halus menggunakan pasir sungai brantas, saringan yang digunakan adalah tertahan saringan no. 16, 30, 50, 100, dan 200. Sumber bahan menapun harus terdiri dari pasir atau pengayakan batu pecah dan terdiri dari bahan yang lolos ayakan No. $8(2,36 \mathrm{~mm})$ sesuai SNI 03-6819-2002. Fraksi agregat halus pecah mesin dan pasir harus ditumbuk terpisah dari agregat kasar.

\subsection{Filler}

Bahan pengisi dapat terdiri atas batu kapur, debu dolomite, semen portland, abu terbang, debu tanur tinggi pembuat semen atau bahkan mineral tidak plastis lainnya. Bahan pengisi mikro agregat ini harus lolos saringan No. $200(0,075 \mathrm{~mm})$. Fungsi bahan pengisi adalah untuk meningkatkan kekentalan bahan bitumen dan untuk mengurangi sifat rentan terhadap temperatur. Bunga pinus banyak terbuang dari pohonnya setelah jatuh. Didaerah yang banyak ditumbuhi pohon pinus, untuk pemanfaatan bunganya sendiri di daerah sumber podang masih belum banyak. Dalam penelitian ini untuk memanfaatkan bunga pinus yang tak terpakai, bunga pinus dimanfaatkan sebagai pengganti filler campuran Aspal beton AC-WC. Karena di daerah 
sumber podang belum ada pemanfaatkan sebagai kerajinan maupun lainnya. Dalam kandungan bunga pinus memiliki sedikit kadar minyak terpentin yang mengandung senyawa terpene biasanya digunakan sebagai pelarut untuk mengencerkan cat minyak, bahan campuran vernis.

\subsection{Tahap Penelitian}

1. Persiapan.

Pada tahap ini yang dilakukan yaitu menyiapkan bahan, dan pengecekkan alat-alat yang akan digunakan. Persiapan bahan seperti aspal, agregat kasar, agregat halus, filler.

2. Pengujian Bahan.

3. Perencanaan Campuran

Ketentuan komposisi agregat campuran AC-WC agregat kasar 65\%, agregat halus 29\% dan Bunga pinus (filler) 6\%. Untuk mendapatkan campuran yang ideal dan memberikan kinerja perkerasan yang optimal maka sebelum membuat campuran diperlukan perencanaan campuran untuk menentukan komposisi masing-masing bahan penyusun campuran agar diperoleh campuran beraspal yang memenuhi spesifikasi antara lain:

a. Pengambilan gradasi agregat cammpuran AC-WC dengan mengambil batas bawah dan batas tengah dari setiap berat lolos saringan dengan acuan spesifikasi Bina Marga 2010

4. Pembuatan dan pengujian benda uji

a. Benda uji dan kadar aspal awal.

Menyiapkan benda uji marshall pada kadar sebagai berikut:

- Untuk dua sampel kadar aspal berada diatas nilai Pb.

- Untuk dua sampel kadar aspal berada dibawah nilai Pb

- Kadar aspal $(\mathrm{Pb})-1,0 \%$

- Kadar aspal $(\mathrm{Pb})-0,5 \%$

- Kadar aspal $(\mathrm{Pb})$

- Kadar aspal $(\mathrm{Pb})+0,5 \%$

- Kadar aspal $(\mathrm{Pb})+1,0 \%$

5. Pengujian dengan Alat Marshall

a. Benda uji direndam dalam water bath selama 30 menit dengan suhu $60^{\circ} \mathrm{C}$.

b. Pembersihan kepala marshall dan diberi pelumas.

c. Meletakkan benda uji pada alat uji marshall yang sudah diberi flow meter dan arloji pembebanan.

d. Pembebanan dilakukan hingga maksimum.

\section{HASIL DAN PEMBAHASAN}


Tabel 1: Hasil pengujian karakteristik Marshall untuk seluruh parameter diambil rata-rata

\begin{tabular}{|c|c|c|c|c|c|c|c|}
\hline No & $\begin{array}{c}\text { Kadar aspal } \\
\text { Minyak }\end{array}$ & VMA \% & VIM \% & VFB \% & Stabilitas & Flow & MQ \\
\hline 1 & $5 \%$ & 15,84 & 3,97 & 74,96 & 1512 & 3,6 & 420 \\
\hline 2 & $5,50 \%$ & 16,42 & 4,61 & 71,90 & 1421 & 3,63 & 392 \\
\hline 3 & $6 \%$ & 16,07 & 4,63 & 71,81 & 1335 & 3,17 & 422 \\
\hline 4 & $6,50 \%$ & 16,96 & 4,11 & 74,32 & 1417 & 3,6 & 394 \\
\hline 5 & $7 \%$ & 16,09 & 4,26 & 73,57 & 1158 & 3,7 & 314 \\
\hline 6 & spesifikasi & $15 \%<$ & $3-5 \%$ & $65 \%<$ & $800 \mathrm{~kg}<$ & $2-4 \mathrm{~mm}$ & $\begin{array}{c}\text { min } \\
\end{array}$ \\
\hline
\end{tabular}

(Sumber : Data Uji Lab. Teknik Universitas Kadiri)

Hubungan kadar aspal Minyak dengan VIM ( voids in Mix)

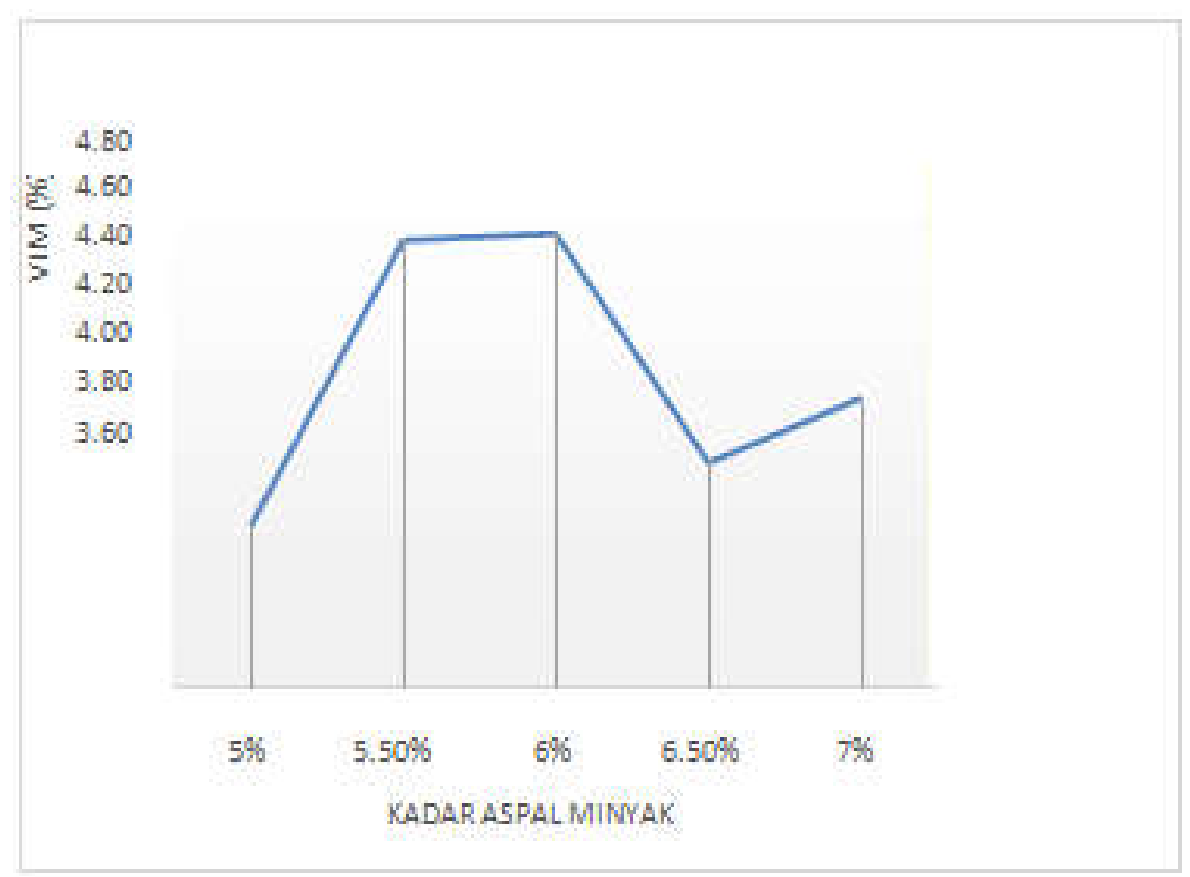

Gambar 1: Gambar untuk hubungan kadar aspal minyak dengan nilai VIM

Hubungan kadar aspal Minyak dengna VMA ( voids Mineral Aggregate) 


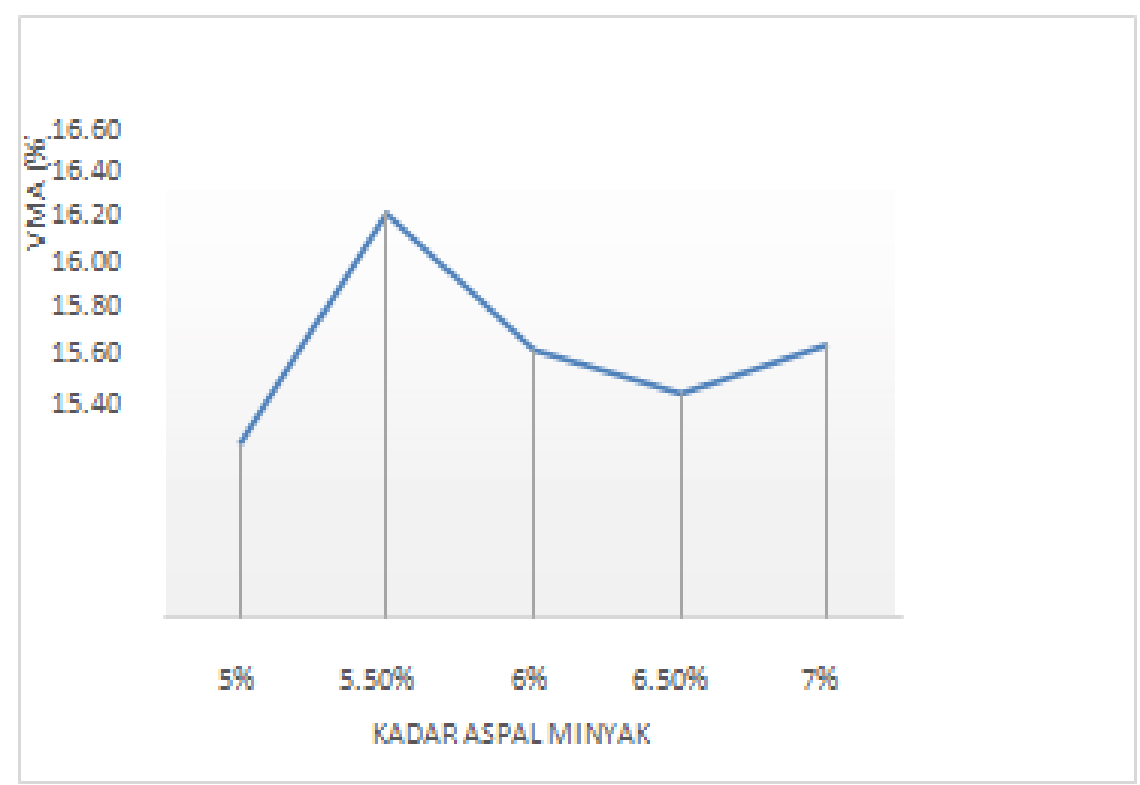

Gambar 2: hubungan antara kadar aspal minyak terhadap nilai VMA

Hubungan kadar aspal Minyak dengan VFB (voids Filled Bitumen)

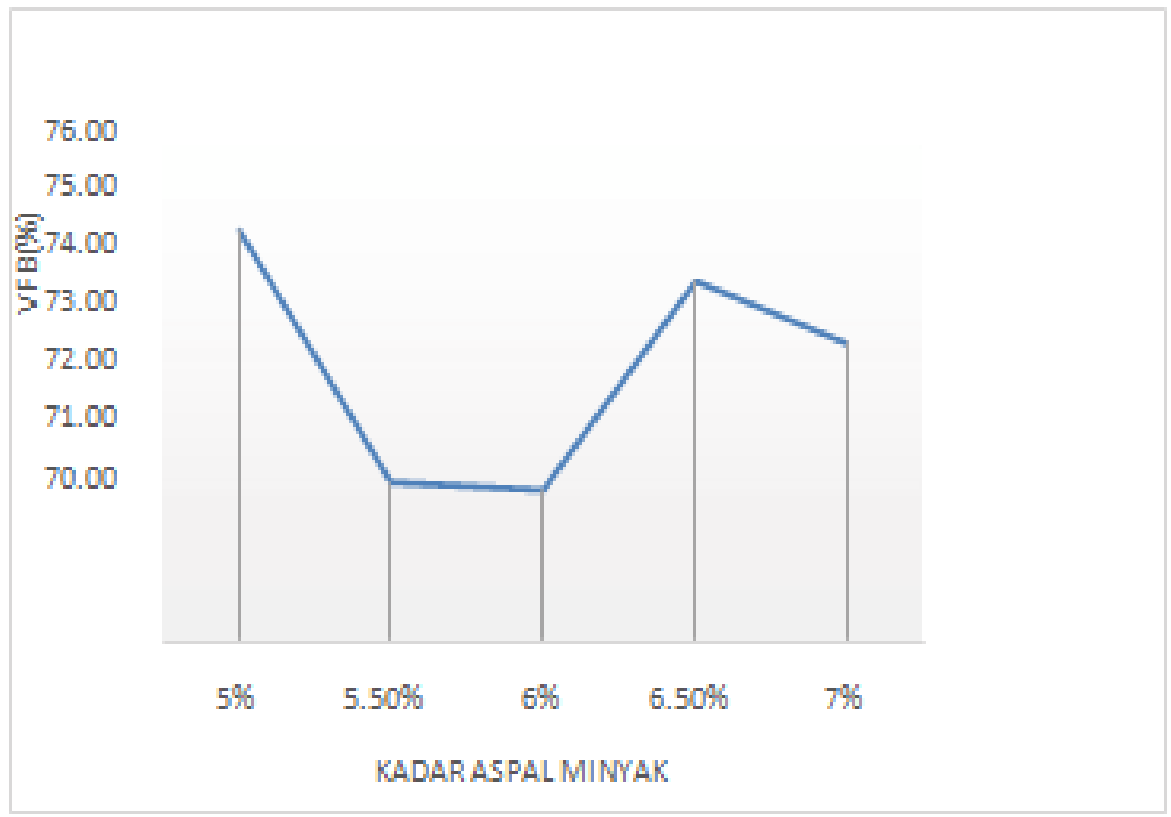

Gambar 3: memperlihatkan hubungan kandungan kadar aspal minyak dengan nilai VFB.

Hubungan kadar aspal Minyak dengan Stabilitas 


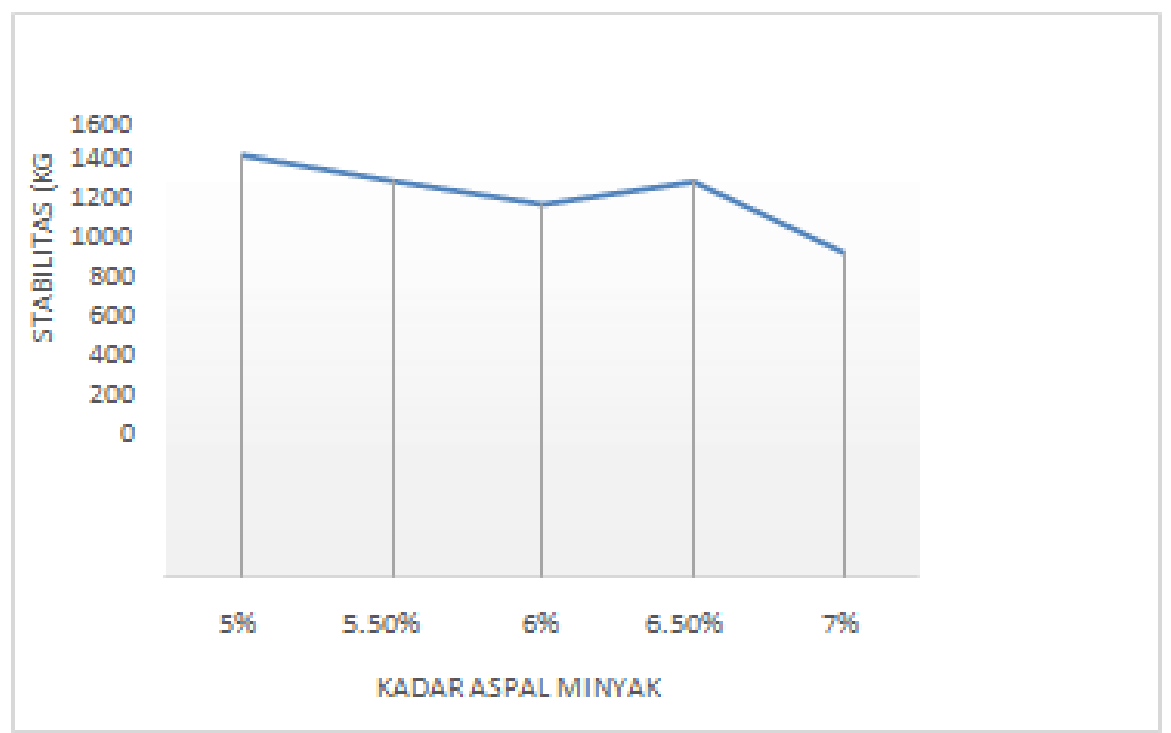

Gambar 4: Gambar hubungan antara kadar aspal dengan nilai stabilitas

Hubungan kadar aspal dengan Flow

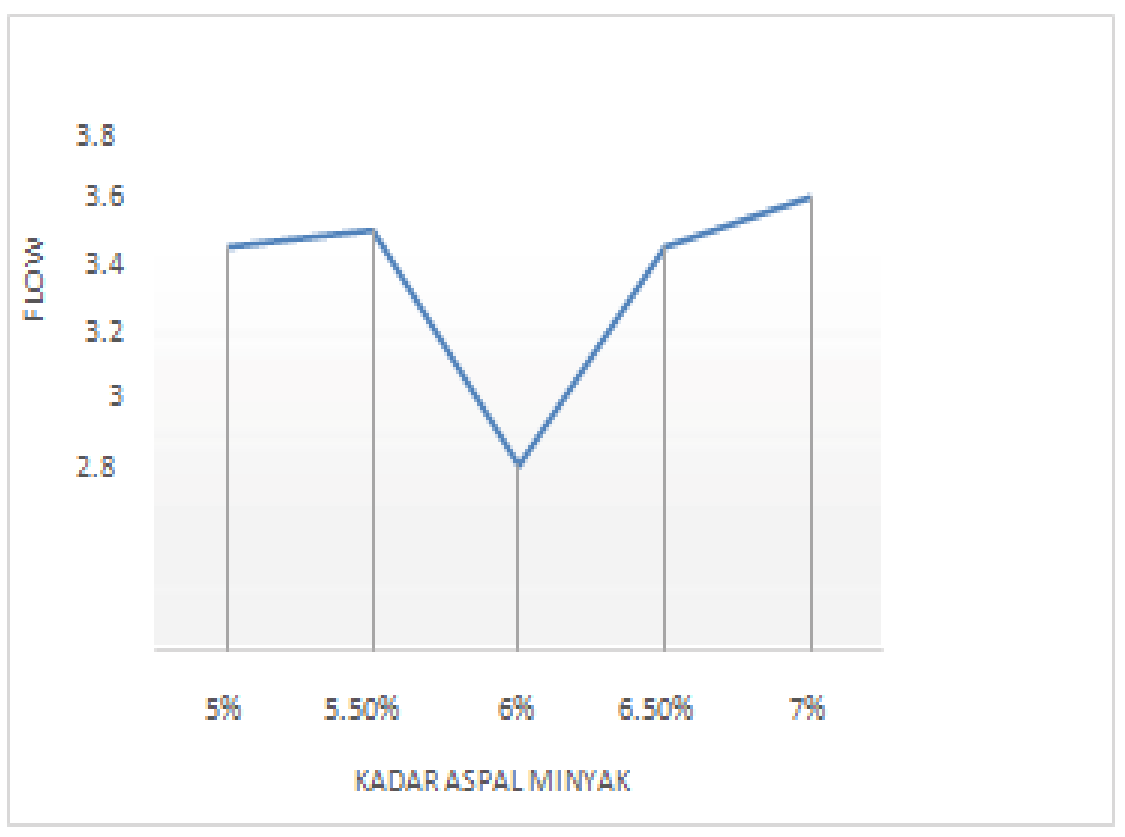

Gambar 5: Hubungan antar Kadar Aspal dengan Nilai Flow 
Hubungan kadar aspal dengan MQ ( Marshall Quetiont)

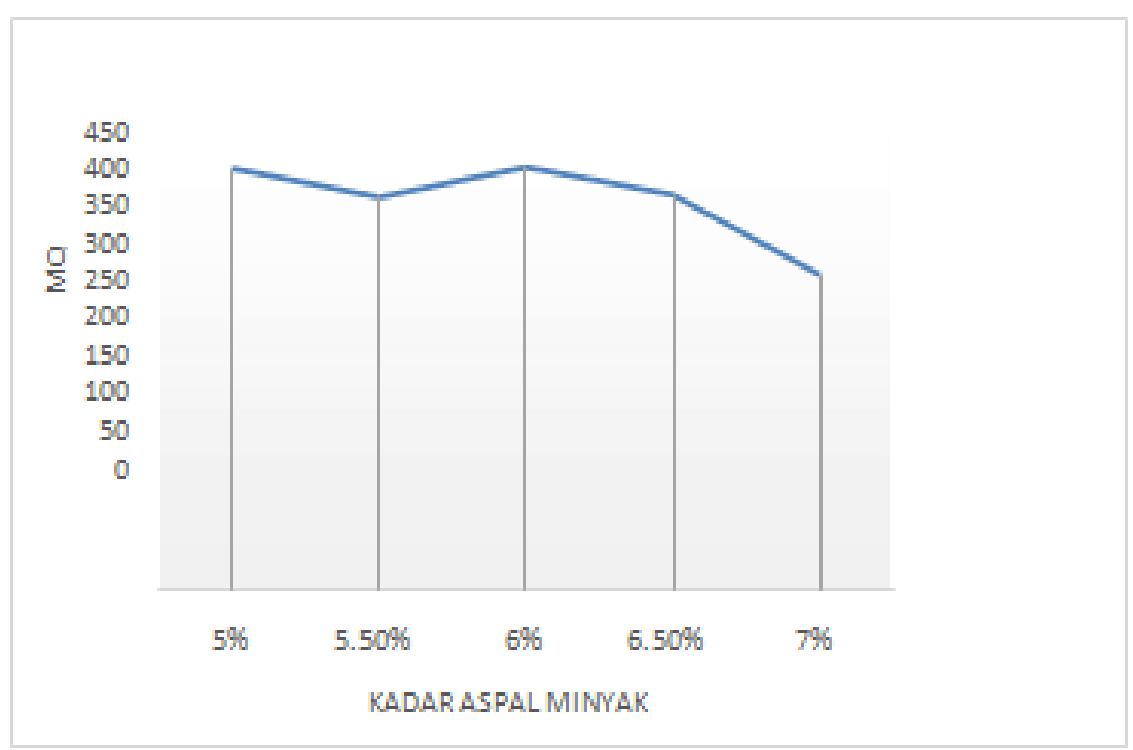

Gambar 6: Hubungan kandungan kadar aspal minyak dengan marshall quetiont.

\section{KESIMPULAN DAN SARAN}

\subsection{Kesimpulan}

Hasil dari pengujian campuran aspal beton dengan menggunakan filler bunga pinus dengan alat marshall yang dilaksanakan di Laboratorium Teknik Universitas Kadiri adalah :

1. Hasil penelitian dari campuran aspal beton dengan menggunakan filler Bunga Pinus dengan 5 sampel pada metode marshall menunjukan hasil, seperti :

- Nilai rata-rata VIM kadar aspal 5\% : 3,97 \% ; 5,5 \% : 4,61 \%; $6 \%$ : 4,63\% ; 6,5\% : 4,11\% ; $7 \%$ : 4,26\%

- Nilai rata-rata VMA kadar aspal 5\%: $15,84 \% ; 5,5 \%: 16,42 \% ; 6 \%: 16,07 \% ; 6,5 \%$ : $16,69 \% ; 7 \%$ : 16,09\%

- Nilai rata-rata VFB kadar aspal 5\%: 74,96 \% ; 5,5\%:71,90\%; 6\%: 71,81\%; 6,5\% : $74,32 \% ; 7 \%$ : 73,57\%

- Nilai rata-rata Stabilitas dengan kadar aspal 5\%: $1512 \mathrm{~kg} / \mathrm{mm} ; 5,5 \%: 1421 \mathrm{~kg} / \mathrm{mm} ; 6 \%$ : $1335 \mathrm{~kg} / \mathrm{mm} ; 6,5 \%: 1417 \mathrm{~kg} / \mathrm{mm} ; 7 \%: 1158 \mathrm{~kg} / \mathrm{mm}$

- Nilai rata-rata Flow dengan kadar aspal 5\% : 3,6 ; 5,5\% : 3,63 ; 6\% : 3,17;6,5\% : 3,6; 7\% $: 3,7$ 
- Nilai rata-rata MQ dengan kadar aspal 5\% : $420 ; 5,5 \%: 392 ; 6 \%: 422 ; 6,5 \%: 394 ; 7 \%$ : 314

2. Berdasarkan hubungan antara kandungan kadar aspal minyak dan seluruh parameter marshall dan volumetrik menggunakan filler Bunga Pinus maka didapatkan kandungan aspal optimum berada pada kadar 6,5\% dari Nilai VIM, VMA, VFB, stabilitas dan MQ.

3. Dari hasil penelitian yang sudah dilakukan didapatkan data yang memenuhi spesifikasi dari Bina Marga dengan Nilai pada Kadar aspal 6,5 \% dengan nilai rerata Stabilitas 1417, nilai rerata Flow 3,6 mm, nilai rerata VIM (voids In Mix ) 4,11\%, nilai rerata VMA (Void In Mineral Agregate) 16,69\%, nilai rerata VFB (Void Filled Bitumen) 73,57\%, dan nilai rerata Marshall quotient (MQ) $314 \mathrm{~kg} / \mathrm{mm}$.

\subsection{Saran}

Dari hasil penelitian didapat, maka saran yang bisa disampaikan yaitu :

- Diharapkan pada penelitian selanjutnya untuk pembuatan filler dengan menggunakan metode pembakaran pada tungku untuk memperoleh abu dengan jumlah yang lebih banyak.

- Dan untuk penelitian selanjutnya diharapkan untuk memakai aspal minyak dengan menggunakan kualitas yang berbeda dan agregat yang kualitas yang berbeda juga untuk mengetahui hasil yang berbeda.

\section{DAFTAR PUSTAKA}

[1]AASHTO. 1990. Standard Specifications For Transportation Materials And Methods of Sampling and Testing. Part I. "Specifications". Fifteenth Edition. Washington,D.C

[2] AASHTO. 1990. Standard Specifications For Transportation Materials And Methods of Sampling and Testing. Part II. "Tests".Fifteenth Edition.Washington,D.C

[3] ASTM D 1559-76 atau AASHTO T-245-90, Rancangan Campuran Berdasarkan Metode Marshall.

[4] Departemen Pekerjaan Umum. 1987. Petunjuk Pelaksanaan Lapis Aspal Beton (Laston) Untuk Jalan Raya.

[5] Departemen Pekerjaan Umum. 1999. Pedoman Perencanaan Campuran Beraspal Panas Dengan Pendekatan Kepadatan Mutlak Jakarta: PT. Mediatama Saptakarya (PT. Medisa). 
[6] Direktorat Jenderal Bina Marga Departemen Pekerjaan Umum Republik Indonesia. 2010. Spesifikasi Umum Divisi 6 hal 38

[7] Direktorat Jenderal Bina Marga Departemen Pekerjaan Umum Republik Indonesia. 2010. Spesifikasi Umum Divisi 6 Perkerasan Aspal

[8] Purwadi, Didik. 2009. Pedoman Penulisan Laporan Kerja Praktik.Semarang: Program Diploma III Jurusan Teknik Sipil, Fakultas Teknik, Universitas Diponegoro.

[9] Rancangan Spesifikasi Umum Bidang Jalan dan Jembatan, Divisi VI Perkerasan Beraspal, Dep. PU, Edisi April 2007

[10] SNI 06-2489-1991. Prosedur Pengujian dengan Metode Marshall

[11] Limantara, A. D., Candra, A. I., \& Mudjanarko, S. W. (2017). Manajemen Data Lalu Lintas Kendaraan Berbasis Sistem Internet Cerdas Ujicoba Implementasi Di Laboratorium Universitas Kadiri. Prosiding Semnastek.

[12] Jaya, R. P., Hassan, N. A., Mahmud, M. Z. H., Aziz, M. M. A., Hamzah, M. O., \& Wan, C. N. C. (2014). Effect of aggregate shape on the properties of asphaltic concrete AC14. Jurnal Teknologi, 71(3).

[13] Sugiyanto, G. (2017). Marshall test characteristics of asphalt concrete mixture with scrapped tire rubber as a fine aggregate. Jurnal Teknologi, 79(2).

[14] Idham, M. K., \& Hainin, M. R. (2015). The effect of incorporating reclaimed asphalt pavement on the performance of hot mix asphalt mixtures. Jurnal Teknologi, 77(32), 117-123.

[15] Norhafizah, M., \& Hainin, M. R. (2016). The effect of coconut shell on engineering properties of porous asphalt mixture. Jurnal Teknologi, 78(72). 